\title{
CIÊNCIA'NATURA
}

\section{The investigation of environmental security of Ladies Park using Crime Prevention through Environmental Design (CPTED) approach - case study- Qom Narges Park}

\author{
Saman Bazregari and Mohadese Ostovareh \\ Department of Architecture, Bandar Abbas Branch, Islamic Azad University, Bandar Abbas, Iran \\ bazregari_s@yahoo.com
}

\begin{abstract}
Environmental security enhancement (based on people understanding about their surroundings) is one of the most important approaches which are considered by advanced societies in the social sciences, management and "environment designing" in order to improve the use of "ladies parks". Safety as an objective and subjective receiving is arising from the structure and layout of the environment. Therefore, to increase it, required criteria and standards should be considered for designing the ladies parks. The aim of this study is to investigate the environmental security of Ladies Park by using Crime Prevention through Environmental Design (CPTED) approach. This is a kind of descriptive and analytical study based on survey using inventory technique. This study expresses the problems of ladies parks by using CPTED approach. The statistical population of this research is Narges Park (Qom, Iran), the first park which has been constructed in the city for women. The results of the study show that women in their exclusive parks look for relaxation away from the masculine environment. The existence of environmental security and preventing people from seeing inside the park is one of the key factors which can increase the parks privacy and create peace of mind for users of the park. To increase the level of security in our environment, this study suggests the spaces proper design according to social cultural and ideological conditions of the city and park landscaping using Crime Prevention Through Environmental Design (CPTED) approach.
\end{abstract}

Keywords: Environmental sense of security. CPTED approach. women's perspective. Narges Park. Qom. 


\section{Introduction}

Crime in modern societies is considered as a social problem which has the adverse impact on the lives of thousands of citizens every year. Serious threats and violence to the lives of people and their assets create significant fear in society. Crimes such as theft, rape, murder, and kidnapping are serious threats against the safety and security of the community. Therefore several strategies are needed for dealing with these complex types of crime and the fear of it for older people, women, parents, children and adolescents. All levels of strategies, such as design, social functioning and legal restrictions, meeting the needs of this field are efficient. In this regard, it should be noted that the designers, architects and related companies can play a crucial role in enhancing the safety and security in the communities. On the other hand, it proves that the society, homeowners, designers, development factors and architects can have a more obvious role in protecting the society control and self control against crime through applying the absolute principles and concepts in design and management of man-made physical environment (Nina Almasifar et al, 1389). The issue of women's safety in public places is relatively new and innovative. Women's safety in urban places will lead to social and economic benefits. Women's sense of security is not just a women's issue. If women feel secure, men and the public space in general will be affected as well (Rose varen, 2005).

In this study we have tried to extract and evaluate the characteristics required to develop operational models in collaborative studies and field data in a physical part of Qom (Narges Ladies Park) after reviewing theories related to mental security of women. It is noteworthy that, in the process of this research, mentioning the studies, indicators and the analytical results related to physical security is ignored. Focus of this article is on social approach and mental (not concrete) security of women.

\section{Necessity of the research}

The necessity of this research can be summarized in the fact that nowadays less attention is paid to urban areas potential to reduce or prevent the crimes. Accordingly, city designer or architect must keep in mind to prevent a designing which reduces the possibility of public scrutiny and increases the access to crime-ridden areas, in the process of designing the urban places or building plans. To generalize and to expand the application of this approach in urban planning demonstrates the capability of this technique in improving the security and its efficacy in urban interventions. Therefore, it seems necessary to take some measures to prevent or at least reduce the rising of urban crime rates in urban areas and provide security for citizens in accordance to the criteria of Iran traditional urbanism. This security will be provided if, in new approaches of urbanism, the element of urban security is paid attention to provide the feasibility of a safe urban.

\section{Purpose}

The aim of this study is to increase the knowledge of users, architects and urban designers about the concepts and principles of CPTED and to determine some new goals for increasing its usage in Islamic culture and societies. The above approach looks for ladies park safety and security. By introducing rules and providing recommendations about the design principles of Ladies Park in Islamic and traditional societies, this research seeks to enhance the man-made environment quality and security for vulnerable groups, especially women.

\section{Research Questions}

1. How can Ladies Park be effective in the reduction and prevention of crime?

2. What does CPTED offer for Ladies Park?

3. How does Narges Park provide environmental security for women?

By offering various schemes and architects offers about providing security to Ladies Park, we can prevent or reduce the crime. Park environmental design should be in a way that it reduces the amount of crime in ladies parks as much as possible. Due to its ease of access and use for women as well as its cozy and safe environment and its high walls, Narges Park has provided security.

\section{The research literature}

Nina Almasi et al (2010), the investigation of environmental security in regional parks as a 
part of the urban environment from the perspective of women using CPTED approach/ Saee Park. According to studies and surveys conducted on security in urban places, as a case study, it can be concluded from the perspective of women about Saee Park that: the recent approach of CPTED, which emphasizes on designing principles to prevent crime, is a method of improving the productivity of the environment that enable us to use the urban environment in its optimal form. All laws have been shaped based on Arabic countries culture. The status of women in modern societies and Muslim countries should be somewhat more prominent to feel secure in entertainment places.

Mohammad Reza Pour Jafari et al (2008), Promoting the environmental security and reducing the urban crime with emphasis on CPTED approach. Lack of attention of architects and urban planners to principles of preventing the environmental crime requires a new approach to implement CPTED principles in designing the buildings or urban structure. This makes it important that these principles can increase citizens' sense of security.

Mohammad Reza Bemanian et al (2009), Effective measure to promote women's safety in urban environments: (Case study, around Tehran Shahr Park), Research on Humanities: Women in Development \& Politics. Security is one of the human rights and basic needs and it is essential to human well-being. Gender is the most influential component among other personality characteristics. Women are more vulnerable than men in the face of insecurity.

This requires a separate analysis of factors affecting improvement of their safety and ultimately improving the overall security of the community. In this field study, the central part of Tehran, around the Shahr Park, which is very crowded, is chosen as the sample. The experimental model has been measured based on the main dimensions, parameters and variables of the study with the direct participation of women. Sense of security derived from the model was measured with the spatial separation of the zone.

\section{The study area}

The study area in this research is the city of Qom. Qom city is the only city in the province and it is the center as well. This province is about 63,114 square kilometers. According to statistics in 2011, the population of this province is about 1151672 people of whom 1095871 cases (15/95\%) live in urban areas, 55798 cases (85/4\%) in rural areas and the rest are nomads (non-residence).

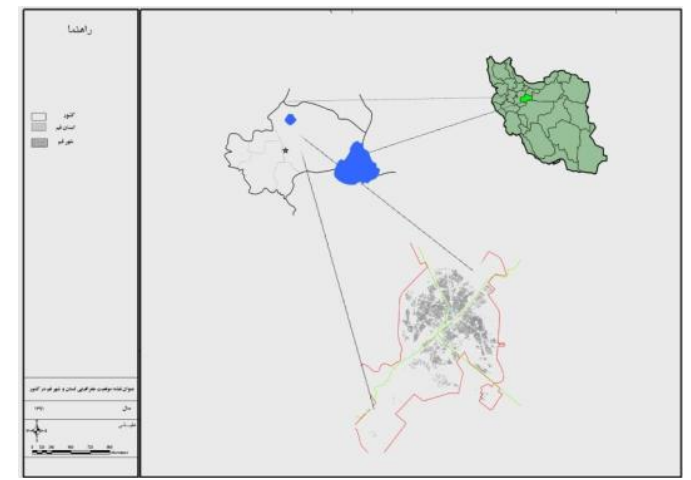

Figure 1- Geographical location of Qom province and cities

Table 1- Population of Qom and its average annual growth during 1986-2011

\begin{tabular}{|c|c|c|c|}
\hline \multirow[t]{2}{*}{ year } & \multirow[t]{2}{*}{ population } & \multicolumn{2}{|c|}{$\begin{array}{c}\text { The average annual } \\
\text { growth }\end{array}$} \\
\hline & & Period & percentage \\
\hline 1986 & 616963 & $\begin{array}{l}1986- \\
1996\end{array}$ & 3.29 \\
\hline 1996 & 853044 & $\begin{array}{l}1996- \\
2006\end{array}$ & 2.07 \\
\hline 2006 & 1046737 & \multirow{2}{*}{$\begin{array}{l}2006- \\
2011\end{array}$} & \multirow{2}{*}{2.65} \\
\hline 2011 & 1151672 & & \\
\hline
\end{tabular}

Source: Statistics Agency of Iran

City of Qom is one of the metropolises of the country which had a significant and unprecedented growth over the past two decades. This growth is due to the migration from rural and urban locations into this city. This led to indiscriminate increase in population and produced some problems such as the imbalance between population and resources, high population density, housing shortage, traffic problems, social aberration and, more importantly, the formation of informal settlement areas. According to official statistics as well as researches, the highest rate of crimes committed in the city of Qom is related to misdemeanour, wickedness and conflict. The city has serious problems in terms of social harms. It seems that identifying the location factors 
facilitating the commission of the crime and omitting them has a significant impact on improving safety and reducing crime rates in this city.

\section{Materials and methods}

This research is an applied developmental research. Its study method is descriptive analytic based on survey. To collect data resulted from field studies; the observing method and questionnaire have been used. To determine the sample size, Cochrane technique has been used (Hafez Niya, 2011). A total of 100 questionnaires were distributed among women who had been randomly selected in the park. In the case of data analysis, the relationship between women's sense of security and environmental designing has been studied. With examination the current situation based on a given set of criteria, we want to judge and evaluate about what they should be. The questionnaire consists of some explanatory questions (specifying the path in the park) and multiple-choice questions. Fixed and control variables are as follows: All questionnaires have been distributed in the area of the park which keeps the fixed space variables. The weather conditions were the same for everyone (atmospheric conditions are under control). Gender was included as a control variable. Questionnaires were completed by women (who are familiar with the site plan) who frequently use the park. Age is also considered in this study. To get the answer, each part of the initial questions has been proposed as several questions in the questionnaire. The questionnaire was designed based on the organizational model of the urban space and CPTED approach. The women were asked to present their intellectual reasons and personal perceptions about the places where they feel insecure.

\section{Theoretical Principles Urban Security}

In a realistic context, researchers have defined security in terms of political and security. In general, most researchers consider it as supporting the values and dealing with hazards and enemies (Baranloo, 2004). Generally, Security can be defined as a fundamental right and a prerequisite for the survival and improving the welfare and health of the people.
According to Maslow's hierarchy of needs theory in 1968, security is one of the basic necessities for human transcendence. It is essential to sustaining life just like human psychological needs. These components promotion directly affects the health and welfare of humans as well as society (World Health Organization report, 1998). Generally, there are two distinctive aspects for explaining the concept of security theory; the concrete aspect and mental aspect. The concrete aspect includes the behavioral and environmental concrete parameters of evaluation. The mental aspect includes the sense of collective security. Both can have positive and negative effects on each other. Therefore, it is necessary to pay attention to these two aspect with together to enhance public safety (World Health Organization report, 1998).

\section{Gender and the sense of security}

Gender has been considered as the most influential personality factor in feeling insecure. The type of crime differs in men and women. Their sense of security is different subsequently. Although it may be less likely than men to be victims of violence in urban public environments, generally, women feel more fear than men. In general, men feel more positive about their own safety than women. For example, both men and women feel unsafe in the darkness, but the degree of insecurity is higher in women (Conference Report, London, 2003: 5). Studies show that women are afraid of being alone in certain circumstances such as some spaces or darkness. For example, in the research on promotion the safety of women conducted in British Columbia in 1992, the overall social analysis in Canada showed that $60 \%$ of Canadian women commonly are terrified of walking alone in their neighbourhood after darkness. $76 \%$ of them are afraid of waiting for public transport after it gets dark. $83 \%$ are afraid of walking alone up to the car in the garage and parking (Feminist Site, 2006). Fear of crime and victimization changes the behavior and the mood in urban public spaces. These effects are more severe on women and other vulnerable social and economic groups. These effects limit their movements, especially make them stayed after darkness and reduce their social, economic and cultural opportunities. In such circumstances, women are excluded from economic and social 
activities such as working late, shifting jobs, evening classes and so on. However, in such cases, women become poorer and victims of crime and the fear of insecurity (Lubova and Metani, 2004).

\section{Security in downtown public spaces}

Recent researches in Australia and other countries show that resorts, shopping centers, markets and other public places are more vulnerable in terms of crime. Commercial and recreational situations influence the crime and criminal behavior as they make their sidewalks and exterior spaces as their own color (Bell, 1998). Due to the existence of operational sample (field study of Qom main center) of this study in this group, we will discuss about security features and international experiences about the security promotion of urban centers in detail in the field studies section. Actually, the downtown has the power to influence the locations which are not related to it. Social functions of urban spaces are related to the "public realm". With the separation of activities, classes, races, ages, genders and so on, public realm will gradually disintegrate to some feeling like fear, suspicion, tension and incompatibility of various social groups (Dayton, 2000). But, according to Verpol (1992), public spaces in urban centers have a naive performance and value as "neutral territory". This means that people can easily be combined without any embarrassment and bafflement. This place is where the values of all people are equal. Fortunately, most people still feel that downtown belongs to everyone (S. Tisdel, 1998).

In 1990, Valentine claimed that "by facilitating the perception of a physical location and informally through design control, you can make women to go out of their houses and increase their presence in urban public areas". He proposed ten designing strategies which often led to physical intervention strategies. Valentine also generalized his approach to the social environment and stated that: "women feel more secure in the actual or potential presence of others". A woman's perception of security is strongly associated with the fact that how she feels comfortable about both physical and social environments and how she knows them. According to him, it can be stated that: "social relationships in a place and the groups controlling that place socially have more energy to make a woman feels secure in the place compared to the place design (Bell, 1998).

\section{Results and discussion}

Ranking the population and its characteristics in age groups, occupational and educational groups are as the following diagram:

The frequency of women were 100 out of which $18.51 \%$ were between $12-20$ years old, $32.7 \%$ were between $20-30$ years old, $21.48 \%$ were between $30-40$ years old and $27.31 \%$ were over 40 years old (Diagram 1).

\section{Diagram 1: The population age groups}

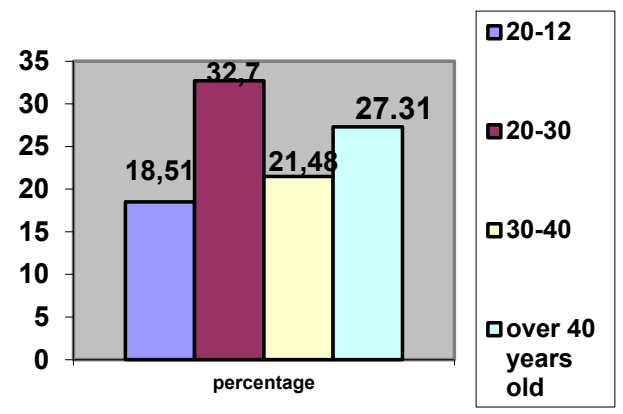

$15.61 \%$ of these women were below the Diploma degree, $25.3 \%$ had Diploma degree, $31.56 \%$ had Associate's degree, $23.6 \%$ had Bachelor's degree and 3.93\% had Master's Degree (Diagram 2).

Diagram 2: The population educational oroisns

Diagram 2: The population educational groups

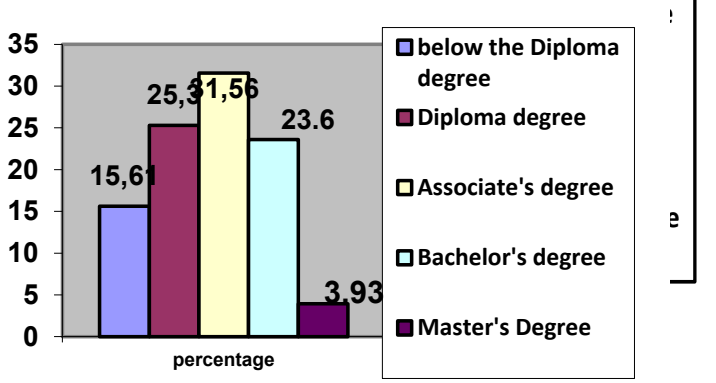

In terms of women location aistance to the park, 35.3\% were far from the park, $11.7 \%$ had normal distance to the park and $53 \%$ were near the park. Also, the results show that most of the women who were studied were living near the park (Diagram 3). 
Diagram 3: The population distance to the Narges Park

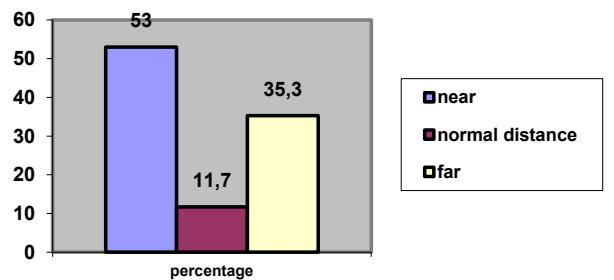

The use of the park during a week was studied in terms of density and the population rate (These studies include a separation by age and educational degree). In Diagram (1) the age and in Diagram (2) the academic degree were shown. According to our investigations, we will be able to specify the places enjoyed more. Image (2), which is marked by the letter A, shows the cycling road used for women walking. Spaces which have been identified by the letters B and C

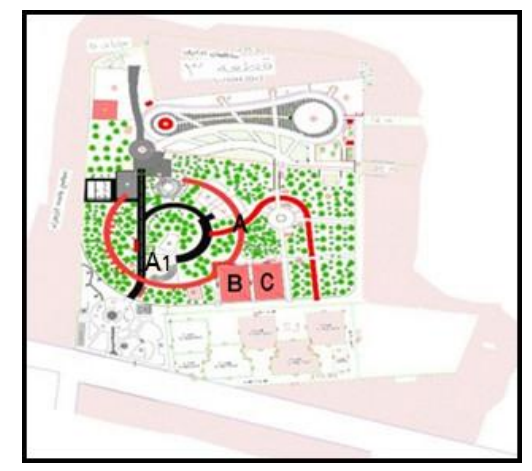

Figure (2) - Based on the results of the questionnaire, the spaces $\mathrm{A}, \mathrm{B}$ and $\mathrm{C}$ are used more

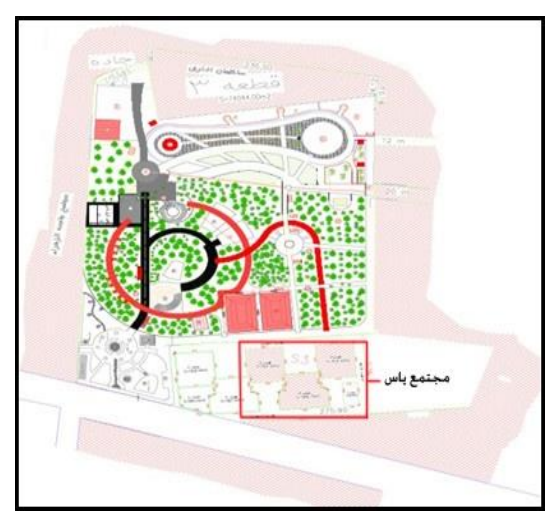

Figure (3) - Based on the results of the questionnaire, the Yas complex is overlooking the park

are those which were used for women walking after the cycling road. This park has no crime- ridden areas. Its only weakness which bothers the women peace of mind is the overlooking of Yas building (Figure 3). This overlooking reduces the use of some places of this park by women.

According to the social, cultural and religious condition of Qom, ladies parks should be completely entertaining, comfortable, secure and without any limitation. Based on the obtained data and increasing rape rate of women in cities, women should have a quick and easy access to the park. Due to the women's safety and comfort, the designing of this park should be in a way that there would be no overlooking building. Women use some parts of the park such as cycling road and green space for walking. All sports and recreational facilities should be provided in this park so that women do not need to go outside the park and face any problem.

Women, who use the park for their own leisure, enjoy the main road of (A1), having the access to all park places, for walking. This road usage by women is $53 \%$. This road was floored by mosaic. 17 percent of women walk through the path of (A) which is longer and has the access to all park places. The places of $B$ and $C$ are used more than other parts. Their only shortage is Yas complex overlooking. Women have a lot of stress to be seen by the naked eye and the camera and try to use the park in a way that not to be seen by people who are living in the complex. To solve this problem, a higher wall can be constructed in the southern part of the park.

\section{Conclusion and recommendations}

According to studies and surveys conducted about the environmental security (a case study of Narges Ladies Park of Qom), it can be concluded that, given the religion condition of Qom, the existence of such a park is needed for women to feel peace of mind and security. It is better to create the roofed parks in all parts of the city for easy accession of women without any insecurity. The park has all the amenities including recreational, sporting, scientific and educational. Its only shortage is Yas complex overlooking. It is also better to employ female staff to satisfy our dear women.

1. Having the regular program of security controls, sending the police patrol and placing 
the kiosks of mobile police considering the crime rate in this area.

2. Eliminating the Yas complex overlooking by constructing a higher wall or roofed places.

3. Employing the female staff for women comfort and sense of security.

4. Increasing the park usage time in summer doe to its long days and warm weather.

5. Separating children's areas from adults' to reduce the accident.

6. Appropriate designing of landscape and environments such as street lighting to increase safety for women.

7. Creating the bus and taxi station near the park for easy access of women and reducing crime and insecurity.

\section{References}

Poor Jafar, Mohammad Reza, Mahmoudi Nejad, Hadi, Rafieeyan, Mojtaba and Ansari, Mojtaba (2008), Improving the environmental security and reducing the civic crime using CPTED approach, nternational Journal of Engineering Science of University of Science and Technology, Volume 19, Issue 16, Pages: 76 to 79 .

Governor of Qom, (2012), Statistical Yearbook of Qom.

Almasi Far, Nina, Ansari, Mojtaba (2010), the investigation of the environmental security in regional park as part of urban spaces, Issue 25, pp: $21-34$.

Bemanian, Mohammad Reza, Rafieeyan, Mojtaba, Zabetiyan, Elham (2009), Assessing the factors affecting the promotion of women's safety in urban environments, Journal, Volume 7, Number 26, pp: 4968.

Report, the World Health Organization (1998): 297.

Conference Report 2003: 5.

Report, the World Health Organization (1998): 271.

Hafez Niya, Mohammad Reza (2013), Research methods in social sciences, Samt Publication, Tehran
Bell, Wendy (1998) women and community safety, Bellplannihg Asso dates soutn Australia, No 32, P 1-26.

Ditton jason (2000) Crimean the city, public attitudes towards open- street CCTvin Glasgow, ox ford, The center for crime and justice studies (ISTD), BRTT.CRIMINoL.

Stiesdel (1998)" fear and gender in public Space, city center management and safer city centers: approaches coventry and nottinghum", university Nottingham institute of urban planning, school of built environment ,pergamon ,uk. "Safety and safety promotion: conoceptualand operational Aspects", world health organization, center on community safety promotion, Karolin's Instituted, Sweden, sptember1998.

Report of the Extractive Industries Transparency Initiative (EITI) London Conference, 17 June 2003

M.Lubuva, johnand Anna Mtani (2004) urban space and security: A case of the Dares salaam, safety Audits for women, Dares salaam, Tanzania, 13-17. Making safer places, women's safety in our cries, National conference, conference Report, London, 18th November 2005.

Rose wame, Louren (2005) the men's gallery, out door advertising and public space: Gen der, fear, and femin ism, Department of political science, university of Melbourne, victoria, women's studies Imitational Forum 28, www. Elsevier. Com/ wsif.

Wad ham, Doro thy (2003) a womonin the public sphere, oxFord University press, English Historical Review.

Www. Feminst. Com, (2006).

Www. PPS.org.2005. 